\title{
Inhibition of USP14 enhances the sensitivity of breast cancer to enzalutamide
}

\author{
Xiaohong Xia ${ }^{1 \dagger}$, Chuyi Huang ${ }^{1 \dagger}$, Yuning Liao ${ }^{1 \dagger}$, Yuan Liu', Jinchan He', Zhiqiang Guo ${ }^{1}$, Lili Jiang ${ }^{1}$, Xuejun Wang ${ }^{2}$, \\ Jinbao Liu ${ }^{1 *}$ and Hongbiao Huang ${ }^{1 *}$
}

\begin{abstract}
Background: Androgen receptor (AR) is expressed in approximately $70 \%$ of breast tumors. Recent studies increasingly support AR as a potential therapeutic target of AR-positive breast cancer. We have previously reported that deubiquitinase USP14 stabilizes AR proteins by deubiquitination and USP14 inhibition results in inhibition of cell growth and tumor progression in AR-positive prostate cancer and breast cancer. The current study aims to explore the anticancer effect of a treatment combining AR antagonist enzalutamide with USP14 inhibition on breast cancer cells.
\end{abstract}

Methods: The combining effects of enzalutamide and USP14 inhibition on breast cancer cell proliferation and apoptosis and associated cell signaling were evaluated in vitro and in vivo.

Results: USP14 inhibition via administration of IU1 or USP14-specific siRNA/shRNA enhanced cell growth inhibition and apoptosis induction by enzalutamide in breast cancer cell lines in vitro and in vivo. Additionally, the combination of enzalutamide with USP14 inhibition/knockdown induced significant downregulation of AR proteins and suppression of AR-related signaling pathways, including Wnt/ $\beta$-catenin and PI3K/AKT pathways. Moreover, AKT inhibition via MK2206 increased the antiproliferative and proapoptotic effects of enzalutamide+IU1 combined treatment.

Conclusion: Collectively, our data suggest that USP14 inhibition in combination with enzalutamide represents a potentially new therapeutic strategy for breast cancer.

Keywords: Breast cancer, Enzalutamide, USP14, Androgen receptor, Combination treatment

\section{Background}

Breast cancer $(\mathrm{BCa})$ is the most common cancer in women worldwide. According to the United States Cancer Statistic, 123 new cases of breast cancer were diagnosed in 100,000 females every year and it has also been estimated that approximately 252,710 cases were found in 2017 in the U.S. The 5-year survival rate of metastatic breast cancer could only achieve $26 \%$, even though some advanced treatments were adopted in the past 20 years [1]. For females, breast cancer is the fifth cause of death and in 2017 roughly 40,610 patients with breast cancer

\footnotetext{
*Correspondence: jliu@gzhmu.edu.cn; hhb800616@126.com

${ }^{+}$Xiaohong Xia, Chuyi Huang and Yuning Liao contributed equally to this work.

${ }^{1}$ Affiliated Cancer Hospital and institute of Guangzhou Medical University; Key Laboratory of Protein Modification and Degradation; State Key Laboratory of Respiratory Disease, School of Basic Medical Sciences, Guangzhou Medical University, Guangzhou 510095, Guangdong, China Full list of author information is available at the end of the article
}

died in the U.S. [2]. Breast cancer is heterogeneous and exists different subtypes with variable outcome and time course. Breast cancer is classified further into four distinctive subtypes depending on the expression of estrogen receptor (ER), human epidermal growth factor receptor 2 (HER2) and progesterone receptor $(\mathrm{PR})[3,4]$. Hormonal therapies aiming at ER, PR and HER2 have long been established and shown significant progress in treating patients with breast cancer [5, 6]. However, an incisive treatment for breast cancer to increase overall survival is deficient. Measures targeting new molecular pathways, such as the use of trastuzumab, tamoxifen and lapatinib to target HER2 and ER, have become important alternative therapies to traditional medications. To date, androgen receptor (AR) has emerged as a promising new therapeutic target in breast cancer therapy [7-9].

(c) The Author(s). 2019 Open Access This article is distributed under the terms of the Creative Commons Attribution 4.0 International License (http://creativecommons.org/licenses/by/4.0/), which permits unrestricted use, distribution, and reproduction in any medium, provided you give appropriate credit to the original author(s) and the source, provide a link to the Creative Commons license, and indicate if changes were made. The Creative Commons Public Domain Dedication waiver (http://creativecommons.org/publicdomain/zero/1.0/) applies to the data made available in this article, unless otherwise stated. 
The AR makes a contribution to the progression and development of breast cancer and is expressed in all stages [10]. Approximately $77 \%$ patients with breast cancer were estimated to be AR positive [11]. Enzalutamide is considered as a potent AR signaling inhibitor approved for the therapy in men with metastatic castration-resistant prostate cancer [12]. Through competitively binding to AR, enzalutamide inhibits nuclear translocation of $A R$, androgen-mediated receptor activation, and the binding of AR to chromatin, resulting in inhibition of AR signaling and thereby leading to growth inhibition of prostate cancer cells, induction of apoptosis of prostate cancer cells and tumor regression in preclinical trials [13-15]. Moreover, it has been demonstrated that patients with breast cancer that express the androgen receptor tolerate enzalutamide well and benefit from enzalutamide treatment, suggesting enzalutamide has a significant antitumor effect and safety in AR positive breast cancer [16].

There are roughly 100 deubiquitinating enzymes (DUBs) in the ubiquitin-proteasome system [17]. Only three DUBs, including USP14, Rpn11, UCHL5, are present in mammalian $19 \mathrm{~S}$ regulatory particles [18]. UCHL5 and USP14 play attractive and versatile roles, given their reversibility in association with the $19 \mathrm{~S}$ proteasome [19]. USP14 is overexpressed in the most cancers and its deubiquitinating activity is activated by the proteasome. USP14 could reduce the anchoring time of ubiquitin conjugates with the proteasome and induce deubiquitination of targeted proteins to stabilize the substrate protein [20]. We have reported that USP14 mediates deubiquitination and stabilization of the AR in prostate and breast cancer cells [21, 22]. USP14 inhibition induced cell cycle arrest and apoptosis and overexpression of AR abrogated significantly the antiproliferative effect induced by USP14 siRNA in $\mathrm{AR}^{+}$breast cancer cells [22].

In the present study, we sought to explore whether both inhibition of AR signal and degradation of AR protein would synergistically inhibit the growth and progression of breast cancer cells. Thus, we tested the combination effect of an AR antagonist (enzalutamide) and USP14 inhibitor (IU1)/siRNA in breast cancer cells. Our results provide strong experimental basis for this combination to become a rational and new therapeutic strategy for AR positive breast cancer.

\section{Methods}

\section{Materials}

IU1 (S7134), enzalutamide (S1250) and MK2206 (S1078) were obtained from Selleckchem (Houston, TX, USA). DMSO was used to dissolve these inhibitors and the inhibitors were stored at $-20^{\circ} \mathrm{C}$. USP14 $(\mathrm{sc}-76,817)$ siRNA was obtained from Santa Cruz Biotechnology (Santa Cruz, CA, USA). MTS (catalog no. G111) was obtained through Promega Corporation (Madison, WI, USA). Annexin V-FITC/PI apoptosis detection kits of Keygen Company (Nanjing, China)(KGA107) were purchased. Cell Lysis Buffer (\#9803) was from Cell Signaling Technology (MA, USA) and stored at $20^{\circ} \mathrm{C}$. Anti-GAPDH (MB001) was obtained from Bioworld Technology (St.Louis Park, MN, USA). The other antibodies were from Cell Signaling Technology (MA, USA): anti-PARP (\#9542), anti-caspase 3 (\#9668), anti-cleaved caspase 3 (\#9661), anti-caspase 8 (\#9746), anti-cleaved caspase 8 (\#9496), anti-cleaved caspase 9 (\#9501), anti-Bax (\#5023), anti-CDK4(\#12790), anti-P27(\#3686), anti-caspase 9 (\#9508), anti-CDK2 (\#2546), anti-CyclinD1(\#2922), anti-total-AKT (\#9272), anti-AR (\#5153), anti-USP14 (\#11931), anti-Bcl-2 (\#15071), anti-GSK3ß (\#12456), anti-p-GSK3ß (Ser9)(\#9323), anti-phospho-AKT (Ser473)(\#4060), anti- $\beta$-catenin (\#8480), anti-EGFR (\#4267), anti-IGF1R (\#9750).

\section{Cell lines and culture conditions}

Human breast cell lines, including MDA-MB453, MCF-7, MDA-MB231, HCC1937 and MDA-MB468, were from American Type Culture Collection (Manassas, VA, USA). HyClone DMEM, 10\% fetal bovine serum (FBS) was prepared to culture cells and cells were maintained at $37^{\circ} \mathrm{C}$ and $5 \% \mathrm{CO} 2$.

\section{Cell viability assay}

As we previously reported, MTS was used to cell growth inhibition [23, 24]. In brief, exponentially growing MDA-MB453, MCF-7, MDA-MB231, HCC1937 and MDA-MB468 cells were digested and suspended at HyClone DMEM medium with 10\% FBS. Then cells randomly were plated onto the 96-well plates with a volume of 100ul cell suspensions. After incubation overnight, the cells were treated with IU1/USP14 siRNA, enzalutamide or the combination of the two treatment for $72 \mathrm{~h}$. $20 \mu \mathrm{l}$ MTS was directly added to well and cells were incubated for an additional $3 \mathrm{~h}$. The absorbance of optical density at wavelength of $490 \mathrm{~nm}$ with microplate reader (Sunrise, Tecan) was read.

\section{Colony formation assay}

Clonogenic assay was performed as previously described [25]. MDA-MB453, MCF-7, MDA-MB231, HCC1937 and MDA-MB468 cells were exposed to IU1 and/or enzalutamide for $48 \mathrm{~h}$. Then cells were digested and suspended in the 6-well plates containing 30\% agarose supplemented with 10\% FBS HyClone DMEM. The cells were cultured in an atmosphere of $5 \% \mathrm{CO} 2$ at $37^{\circ} \mathrm{C}$ for 10-14 days and washed with $4{ }^{\circ} \mathrm{C}$ PBS. $4 \%$ polyformaldehyde was added into 6-well plates to fix cells for $15 \mathrm{~min}$ and then crystal violet solution was diluted to $1 \%$ and used to stain cell for $5 \mathrm{~min}$. Colonies $>60 \mu \mathrm{m}$ were counted and the experiments were done in triplicate. 


\section{EdU staining}

The cell proliferation was detected with Cell-Light ${ }^{\text {tax }}$ EdU Apollo 567 In Vitro Kit (Cat number: C10310-1, RiboBio, Guangzhou, China). Exponentially growing cells were digested and seeded at chamber slide overnight. The cells were exposed to IU1, enzalutamide or the combination for $48 \mathrm{~h} .50 \mu \mathrm{mol} / \mathrm{L}$ Edu were added into chamber slide at $37^{\circ} \mathrm{C}$. After incubation for $2 \mathrm{~h}$, the cells were washed with PBS twice and fixed with $4 \%$ paraformaldehyde for $30 \mathrm{~min}$. Then $2 \mathrm{mg} / \mathrm{ml}$ glycine were used to incubate the cells for $5 \mathrm{~min}$ and washed with PBS. $0.5 \%$ Triton X-100 was used to incubate cell for $10 \mathrm{~min}$ and cell was washed with PBS once. Apollo reaction cocktail containing annexing agent buffer, fluorochrome, catalytic agent and Apollo reaction buffer was already to incubate cells. After $30 \mathrm{~min}, 0.5 \%$ Triton X-100 was used to wash cell for $10 \mathrm{~min}$ twice. Fluoroshield mounting medium with DAPI was added for DNA staining in dark. Image were captured using an Olympus microscope from three independent repeated experiments.

\section{Flow cytometry analysis of cell cycle and apoptosis}

Apoptosis assay was performed according to previous description [26]. MDA-MB453 and MCF-7 cells treated IU1 and/or enzalutamide for indicated time were harvested and washed with PBS twice. Then $500 \mu \mathrm{l}$ binding buffer was already to suspend cells. Annexin V-FITC/ PI was added into tube and incubated for $15 \mathrm{~min}$ in dark, followed were detected by flow cytometry.

For cell cycle assay, cells were exposed to either IU1, enzalutamide or the combination of both IU1 and enzalutamide for indicated time. Cells were digested by trypsinization and then washed with cold PBS twice. Then cells were suspended and fixed with $500 \mu \mathrm{l}$ PBS and $2 \mathrm{ml} 70 \%$ ethanol overnight. Lastly, PBS was used to wash cells thrice and cells were incubated with PI, RNase A and 0.2\% Triton X-100 complexes for $30 \mathrm{~min}$ at $4{ }^{\circ} \mathrm{C}$ in dark.

\section{SiRNA transfection}

As previously described [27], MDA-MB453 cells were harvested and seeded in plates or dishes overnight. $500 \mu \mathrm{l}$ RPMI opti-MEM and $5 \mu \mathrm{l}$ lipofectamine RNAimax (Invitrogen) reagent mixtures were prepared. SiRNA targeting human USP14 or siRNA with non-specific sequences were added into the mixtures. The cell was incubated with mixtures. After transfection for $6 \mathrm{~h}, 10 \% \mathrm{FBS}$ HyClone DMEM was replaced and incubated for additional $42 \mathrm{~h}$.

\section{Lentivirus USP14 shRNA transfection}

Lentiviruses (pLent-4in1shRNA-GFP) expressing control shRNA or human USP14-speicfic shRNA (NM-005151) were purchased from VigeneBio (Shandong, China). Cultured cells were digested and plated into $6 \mathrm{~cm}$ dishes. After $24 \mathrm{~h}$, polybrene (Santa Cruz, CA, USA) and lentivirus mixtures were dissolved in medium and added into each well. When cells were incubated overnight, supernatant was replaced with fresh medium and cultured for $48 \mathrm{~h}$. In order to select stably-transfected cells, puromycin (Santa Cruz, CA, USA) was used at the concentration of $2 \mu \mathrm{g} / \mathrm{ml}$ to perform the selection.

\section{Western blot}

This assay was performed as we previously reported [28]. Breast cancer cell was exposed to the indicated treatment and the total proteins were extracted using cell lysis buffer. Collected proteins were quantitated using BCA protein assay kit. The protein samples were prepared and then separated by SDS-PAGE. Then the fractionated proteins were transferred to PVDF membranes. Lastly, to block bolts, the membranes were incubated with $5 \%$ defatted milk powder for one hour and PBS-T were used to wash the membranes for three times for $5 \mathrm{~min}$. Importantly, the membranes were incubated with primary antibodies at $4{ }^{\circ} \mathrm{C}$ overnight and washed with PBS-T for $6 \mathrm{~min}$ thrice. Secondary antibodies were used to incubate the membranes. After $1 \mathrm{~h}$, the membranes were washed with PBS-T for $6 \mathrm{~min}$ for thrice. Lastly, the ECL detection reagents were used to react with bounded secondary antibodies and exposed to X-ray films (Kodak, Japan).

\section{Immunofluorescence assay}

Immunoflurescence assay was performed as we described previously [22]. MDA-MB453 cells were treated with IU1/USP14 siRNA, enzalutamide or the combination for indicated time. The medium was removed and PBS was used to wash. Then $4 \%$ paraformaldehyde for $15 \mathrm{~min}$ to fix the cells, followed by permeabilization with 0.1\% Triton X-100 (Solarbio Life Science). After $10 \mathrm{~min}$, cells were blocked with 5\% BSA and then primary antibody diluted with $1 \%$ BSA was used to incubate overnight at $4^{\circ} \mathrm{L}$. Lastly, the incubated of secondary Cy3-conjugated antibody was performed and fluoroshield mounting medium with DAPI (Abcam) was used. Image were captured using fluorescence microscope in three times.

\section{Luciferase reporter promoter assay}

MDA-MB453 and MCF-7 cells were seeded into 24-well plates for $24 \mathrm{~h}$. The mixture containing $500 \mu \mathrm{l}$ RPMI opti-MEM, $5 \mu \mathrm{l}$ iMAX and $1000 \mathrm{ng}$ luciferase reporter was added into cells for $24 \mathrm{~h}$. Then cells were treated with IU1, enzalutamide or USP14 siRNA for the indicated time. The activity of luciferase was measured using dual luciferase assays kit according to the manufacture's instructions.

\section{Nude mouse xenograft model}

The mice were purchased from Guangzhou University of Chinese Medicine and animal protocols were approved by 
the Institutional Animal Care and Use Committee of Guangzhou Medical University. The nude BALB/c mice (18-22 g, female) were housed in quarantine room for inspection for 2-3 days. Then mice were transferred to barrier facilities in the animal facility of Guangzhou Medical University. Water and food were available ad libitum. After then, the healthy mice were subcutaneously inoculated with MCF-7 cells or MCF-7 cells stably expressing USP14 shRNA or control shRNA in the left armpit. After one month, the inoculated mice were randomly divided into $4 \times 4$ groups and orally administered with IU1 (40 $\mathrm{mg} / \mathrm{kg} / \mathrm{d})$ and $/$ or enzalutamide $(25 \mathrm{mg} / \mathrm{kg} / \mathrm{d})$ for 17 days. Tumor volumes were calculated and mouse body weight were measured every other day.

\section{Immunohistochemical staining}

According to standard techniques as we previously reported $[29,30]$, fixed xenografts were embedded in paraffin and sectioned. The tumor sections were immunostained using MaxVision kits (Maixin Biol). Then the tissue samples were subjected to immunohistochemistry using AR, USP14,Ki67 and p-AKT. Each slide was added using $50 \mu \mathrm{l}$ MaxVisionTM reagent and stained with $0.05 \%$ diaminobenzidine and $0.03 \% \mathrm{H} 2 \mathrm{O} 2$ in $50 \mathrm{mM}$ Tris- $\mathrm{HCl}$ (pH 7.6). Hematoxylin was used to counterstain the slides. The primary antibodies were determined with DAB.

\section{TUNEL staining}

Apoptosis cells of subcutaneous tumor in breast cancer were detected by terminal deoxynucleotidyl deoxyuridine triphosphate nick-end labeling (TUNEL) assay. The paraffin-embedded sections of breast tumor firstly baked at $60^{\circ} \mathrm{C}$ for $30 \mathrm{~min}$. Then the sections were dewaxed with xylene at $50^{\circ} \mathrm{C}$ for $30 \mathrm{~min}$ followed by gradient alcohol and proteinase $\mathrm{K}$ for 20 $\min$ at $37^{\circ} \mathrm{C}$. The sections were washed with PBST for three times and soaked in $3 \% \mathrm{H}_{2} \mathrm{O}_{2}$. TUNEL reaction mixture buffer was used to incubate with the sections for $1 \mathrm{~h}$ and then the sections were incubated with converter-POD for additional $30 \mathrm{~min}$ at $37^{\circ} \mathrm{C}$ in dark. Finally, the sections were reacted with $\mathrm{DAB}$ for $3 \mathrm{~min}$ and the images were captured by a fluorescence microscope.

\section{Statistical methods}

The data of all experiments were from three independent experiments that applicable and are presented as mean \pm SD. Unpaired Student's $t$ test or one way ANOVA were used to determine statistical probabilities. Graph Pad Prism 5.0 software (GraphPad Software) was applied for statistical analysis and $P$ value less than 0.05 was considered statistically significant.

\section{Results}

High expression of USP14 in breast cancer tissues and its correlation to AR expression

The results from analyzing the TCGA database suggested that the mRNA expression of USP14 in all subtypes of Bca tissues was remarkably higher than in normal tissues (Fig. 1a). To explore the relationship between USP14 and AR, we analyzed the expression levels of USP14 in AR positive breast cancer. The results show a statistically significant positive correlation between USP14 expression and AR expression in breast cancer (Fig. 1b), suggesting that the increased USP14 expression might have resulted from elevated AR expression.

\section{Enzalutamide and USP14 inhibition synergistically inhibits the proliferation of breast cancer cells}

To assess the antiproliferative effects of enzalutamide in different doses, alone or in combination with USP14 specific inhibitor IU1 [31] on breast cancer cells, we used an MTS assay to test cell viability on a panel of 5 breast cancer cell lines. We found that either enzalutamide or IU1 alone induced cell growth inhibition in a concentration-dependent manner. Importantly, the combination of enzalutamide and IU1 showed a significantly greater inhibitory effect either agent alone (Fig. 2a). In our previous study, we have detected AR protein expression in all of the five breast cancer cell lines used here: MDA-MB453, MCF-7, MDA-MB468, MDA-MB231 and HCC1937; however, the highest AR protein expression was found in MDA-MB453 and MCF-7 cell lines [22]. Therefore, MDA-MB453 and MCF-7 cell lines were selected as the main targeted cells to test the effect of enzalutamide in combination with IU1. To corroborate that the enhancement effect of IU1 in the combined treatment is through USP14 inhibition, we also tested whether genetic inhibition of USP14 would yield similar effects using USP14 small interfering RNA (siRNA) to knock down USP14 expression in MDA-MB453 and MCF-7 cells. USP14 knockdown induced significant cell growth inhibition and increased enzalutamide-induced antiproliferation effect (Fig. 2b). Furthermore, overexpressing USP14 partly rescued cell growth inhibition induced by enzalutamide (Additional file 1: Figure S1e), suggesting that the combination induced cellular events dependent on USP14 status. Next, we further tested the long-term effect of enzalutamide, IU1, or a combination of both on the five breast cancer cell lines mentioned above using the colony formation assay. As shown in Fig. 2c, the colony forming ability of the cells treated with either enzalutamide or IU1 alone was decreased than that of the cells treated with vehicle control but, more remarkably, this decrease in colony formation was more pronounced in the cells treated with a combination of enzalutamide and IU1. Edu is a thymidine 

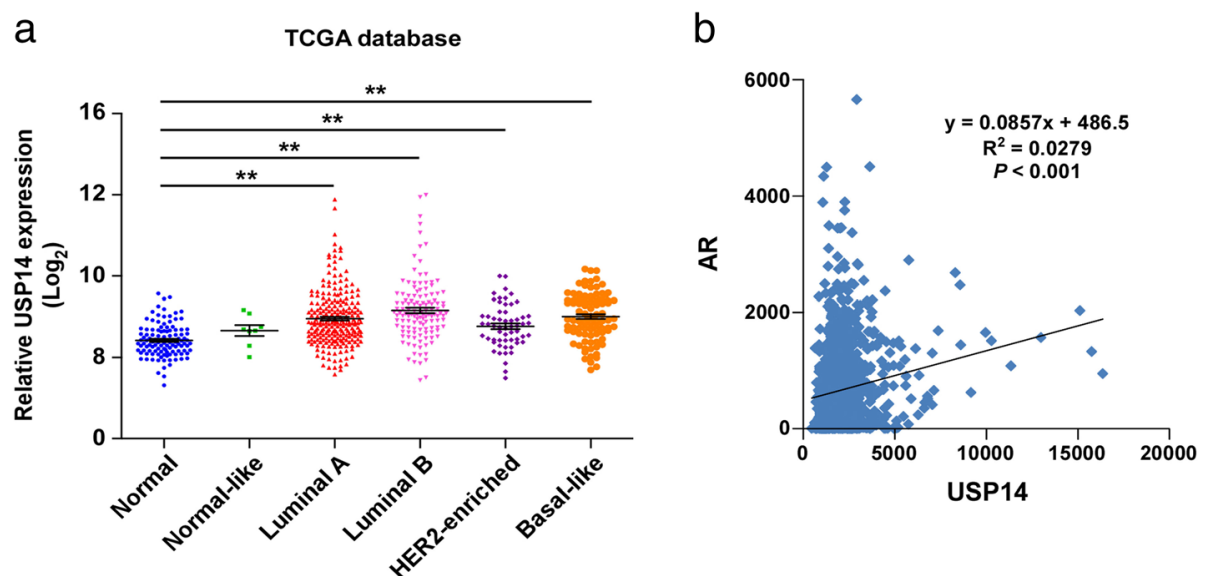

Fig. 1 High expression of USP14 in breast cancer tissues and its correlation to AR expression. a Data of USP14 expression in breast cancer and normal tissues from the TCGA database were analyzed and presented. Each dot represents a patient sample (Normal, $n=113$; Normal-like, $n=8$; Luminal A, $n=231$; Luminal B, $n=127$; HER2-enriched, $n=58$; Basal-like, $n=97) .{ }^{*} P<0.01$. b The correlation of USP14 expression with AR expression in AR-positive breast cancer tissues was detected by analyzing TCGA database $(n=1095)$

analog and can be incorporated into the replicating chromosomal DNA during the $S$ phase of cell cycle, which is exploited for detection of DNA synthesis in the Edu labeling assay [32]. To further determine whether enzalutamide and IU1show synergy in the antiproliferative effect on breast cancer cells, we performed Edu labeling assay on MDA-MB453 and MCF-7 cells exposed to enzalutamide,IU1, or a combination of both. We found that the percentage of cells positively labeled with Edu in the group received the treatment combining enzalutamide and IU1 was drastically lower than that in the groups treated with either agent alone (Fig. $2 \mathrm{~d}$ and e). These results compellingly demonstrate that enzalutamide and IU1 synergistically enhances each other's antiproliferative effects in breast cancer cells.

\section{Induction of apoptosis by the co-treatment of} enzalutamide and USP14 inhibition in breast cancer cells

To further explore the mechanism of the antiproliferative effect induced by enzalutamide in combination with IU1, we next investigated whether apoptosis was triggered and involved in cell growth inhibition. Induction of apoptosis in MDA-MB453 and MCF-7 cells after $48 \mathrm{~h}$ of treatment with enzalutamide, IU1, or a combination of the two was assessed with flow cytometric analyses of Annexin V-FITC/PI stained cells. We found that less than $10 \%$ of cells in the enzalutamide or IU1-treated groups underwent apoptosis but the treatment combining enzalutamide with IU1 increased the apoptotic cell percentage to more than $20 \%$ in both cell lines. Also, when siRNA-mediated USP14 knockdown was used to replace the IU1 treatment in MDA-MB453 cells, similar results were obtained (Fig. $3 a$ and $b$ ). We further measured the expression level of proteins associated with apoptosis. Neither IU1 nor enzalutamide alone induced significant cleavage of the 113-kDa PARP to the $89-\mathrm{kDa}$ fragment in MDA-MB453 and MCF-7 cells. However, the $89-\mathrm{kDa}$ apoptotic fragment of PARP was remarkably induced in the combined treatment of enzalutamide and IU1. Importantly, apoptotic "executioners" including the cleaved caspase $-3,-8,-9$ were increased in the co-treatment group, compared with the single agent treatment groups in MDA-MB453 and MCF-7 cells (MCF-7 is deficient of caspase-3), suggesting that caspase plays a critical role in apoptosis induced by co-treatment of enzalutamide and IU1. The BCL-2 family are known to regulate cancer cell survival and death and are closely related to the apoptotic pathway [33]; hence, we also measured the expression of Bax and Bcl-2, two main majors in the BCL-2 family using western blot analyses. We found that the anti-apoptotic protein Bcl-2 was decreased and pro-apoptotic protein Bax was increased by the treatments. More importantly, the downregulation of $\mathrm{Bcl}-2$ and upregulation of Bax were more pronounced in the combined treatment group. USP14 siRNA in combination with enzalutamide induced similar results in MDA-MB453 cells (Fig. 3c). These results suggest that the antiproliferative effect induced by treatment combining enzalutamide with USP14 inhibition is associated with cell death.

\section{The treatment combining enzalutamide with USP14 inhibition arrests cell cycle progression}

The deregulation of cell cycle is linked to oncogenesis in various cancers [34]. To explore the mechanisms underlying the synergistic antiproliferation effect between enzalutamide and USP14 inhibition, we determined their effects on cell cycle progression using flow cytometry 


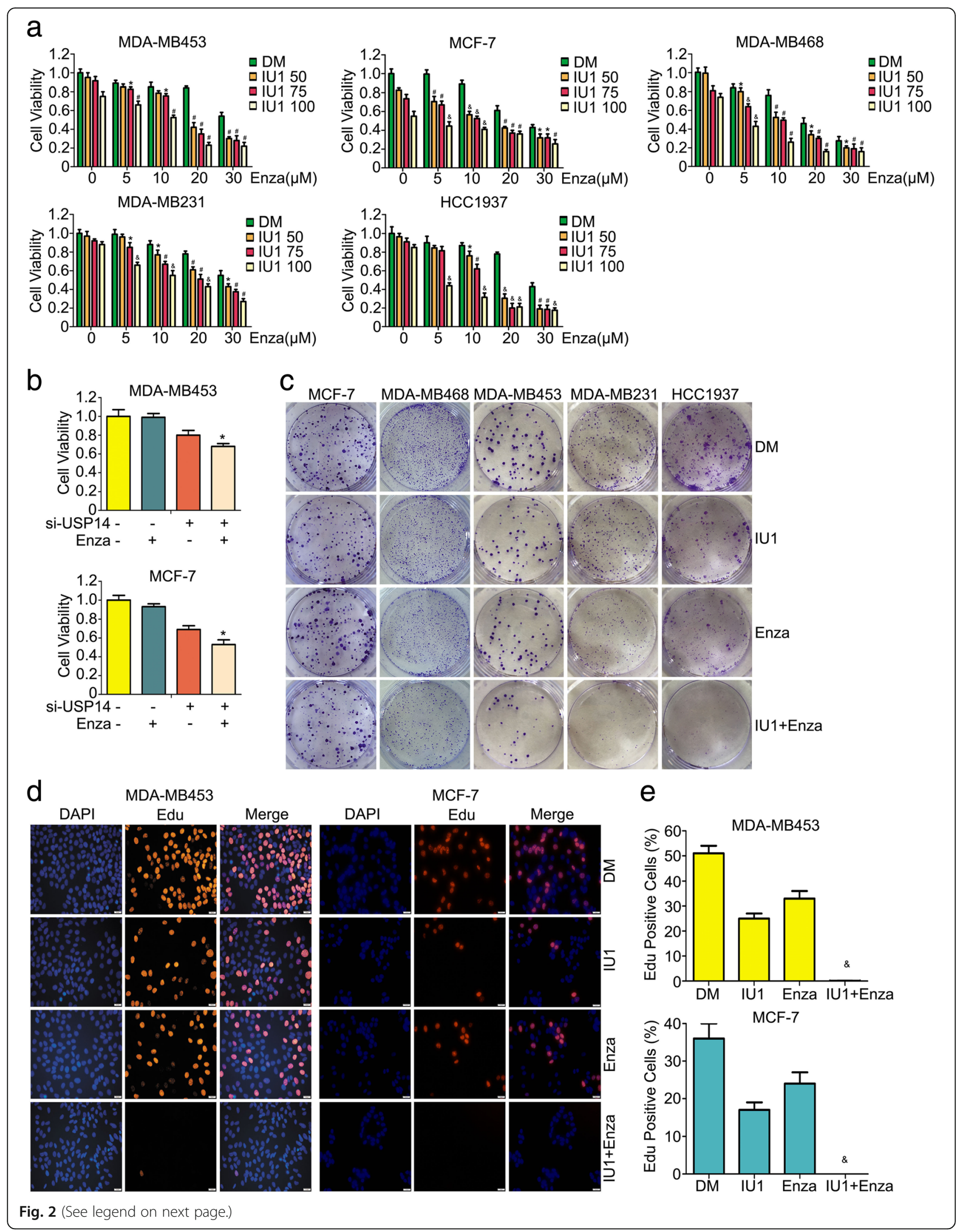


(See figure on previous page.)

Fig. 2 Enzalutamide and USP14 inhibition synergistically suppress the proliferation of breast cancer cells. a MCF-7, MDA-MB453, MDA-MB231, MDA-MB468 and HCC1937 cell lines were plated in 96-well plates and exposed to enzalutamide (Enza; 0, 5, 10, 20, 30 MM), USP14 inhibitor (IU1: 0, $50,75,100 \mu \mathrm{M})$, or the combination of enzalutamide +USP14 inhibitor for $72 \mathrm{~h}$ in triplicates. Cell viability was measured after adding $20 \mu \mathrm{l}$ MTS for $2 \mathrm{~h} .{ }^{*} p<0.05,{ }^{\#} p<0.01,{ }^{\&} p<0.001$ vs. each treatment alone. DM: DMSO. b The indicated breast cancer cells in cultures were treated with USP14speicfic siRNA (si-USP14, $30 \mathrm{nM}$ ), enzalutamide $(20 \mu \mathrm{M})$, or both for $72 \mathrm{~h}$ in triplicates and then subject to the MTS assay. ${ }^{*} p<0.05 \mathrm{vs}$. each treatment alone. c The indicated 5 breast cancer cell lines were treated with enzalutamide (Enza, $20 \mu \mathrm{M})$, IU1 (75 $\mu \mathrm{M}$ ), or the combination of the two agents for $48 \mathrm{~h}$ before they were used for the colony formation assay in which the treated cells were re-plated in 6-well plates cultured for approximately 10 days before processed for detection of the colonies. Representative images are shown. $\mathbf{d}$ and (e) Cell proliferative ability was detected using Edu staining in MDA-MB453 and MCF-7 cells treated with enzalutamide (Enza, $20 \mu \mathrm{M})$, IU1 (75 $\mu \mathrm{M})$, or the combination of both (IU1 + Enza) for $48 \mathrm{~h}$. Nuclei were stained with DAPI. The representative images (d) and pooled data (e) from three independent experiments are shown. Scale bar, $50 \mu \mathrm{m} .{ }^{\&} \mathrm{p}<0.001$ vs. each treatment alone

analysis and on the protein expression of key cell cycle regulators using western blot analyses. We found that both enzalutamide and IU1 or USP14 siRNA arrested cell cycle progression at the G0/G1 phase. Importantly, $90 \%$ or more of the cells subject to the treatment combining enzalutamide with IU1 or with USP14 siRNA were arrested at the G0/G1 phase, remarkably greater than that of the cells treated with enzalutamide or USP14 inhibition alone (Fig. 4a and b). Cyclin D1, CDK4, CDK2, and P27 are key regulators for the G1 to $\mathrm{S}$ phase transition. Our western blot analyses showed that the expression of CDK4, CDK2 and Cyclin D1, which promote cell cycle progression, were decreased and P27 which blocks cell cycle at G0/G1 phase was increased by treatment with enzalutamide, IU1, or USP14 siRNA. Furthermore, these changes were more remarkable in the cells treated with a combination of enzalutamide with IU1 or USP14 siRNA (Fig. 4c). These results are in agreement with the flow cytometry data, indicating that the treatment combining enzalutamide with USP14 inhibition induces cell cycle arrest at G0/G1 phase potentially; these findings also suggest that the cell cycle arrest is mediated by decreasing CDK4, CDK2, and Cyclin D1 and increasing P27 protein expression.

\section{The treatment of combining enzalutamide with and IU1 or USP14 knockdown induces the downregulation of AR and inhibits AR-related signaling pathways}

The protein level of AR is significantly associated with disease outcome in breast cancer [35]. Importantly, AR may be considered as a target in the standard chemotherapeutic regimen for breast cancer. Next, we tested the effect of the treatment combining pharmacological or genetic inhibition of USP14 inhibition with enzalutamide on AR protein expression and signaling. Western blot analyses showed that enzalutamide promoted the downregulation of AR protein induced by IU1 or USP14 siRNA (Fig. 5a). The cross-talks exist between AR and other molecules that have been regarded as significant biological targets in clinical trials. Androgen receptor could regulate the expression of IGF-1 receptor (IGF-1R) via a non-genomic pathway [36]; for example, the re-expression of AR in M12 prostate cancer cells increased IGF-1R expression [37]. In addition, overexpression of AR results in an increase in the protein level of epidermal growth factor receptor (EGFR) [38]. We found that the treatment combining IU1 or USP14 siRNA with enzalutamide remarkably decreased the expression of IGF-1R and EGFR proteins (Fig. 5a). AR expression is associated with the PI3K signaling pathway [39]. The wnt/ $\beta$-catenin are involved in AR signaling. The phosphorylation of GSK-3 $\beta$ by AKT mediates abnormal expression of $\beta$-catenin and $\beta$-catenin has impact on the transactivation of AR to drive the progression in cancer [40]. As shown in Fig. 5a, the combination of enzalutamide with USP14 inhibition more remarkably inhibited PI3K and wnt/ $\beta$-catenin signaling pathways, compared with the single drug treatment. These findings suggest that the combination of USP14 inhibition with enzalutamide decreases AR protein expression and inhibits AR-related intracellular signaling pathways. To further explore the role of USP14 inhibition and enzalutamide on AR, we sought to determine whether they could interfere AR nuclear translocation by performing immunofluorescent staining assays to observe AR protein distribution and expression in MDA-MB453 cells. We found that the AR immunofluorescence in the cells received the co-treatment of enzalutamide with IU1 or with USP14 siRNA was markedly less intense than in those received the single agent treatment; however, the nuclear and cytoplasmic distribution of AR staining was comparable among different treatment groups (Fig. 5b), indicating that the combined treatment exerts its synergistic effect on suppressing AR signaling mainly through reducing AR protein levels not suppressing AR nuclear translocation in breast cancer cells. Additionally, we asked whether the combination of enzalutamide and USP14 inhibition alter AR-mediated transcription activity. The results of luciferase reporter assay reveal that AR-mediated transcription activity is inhibited by the co-treatment of enzalutamide and USP14 


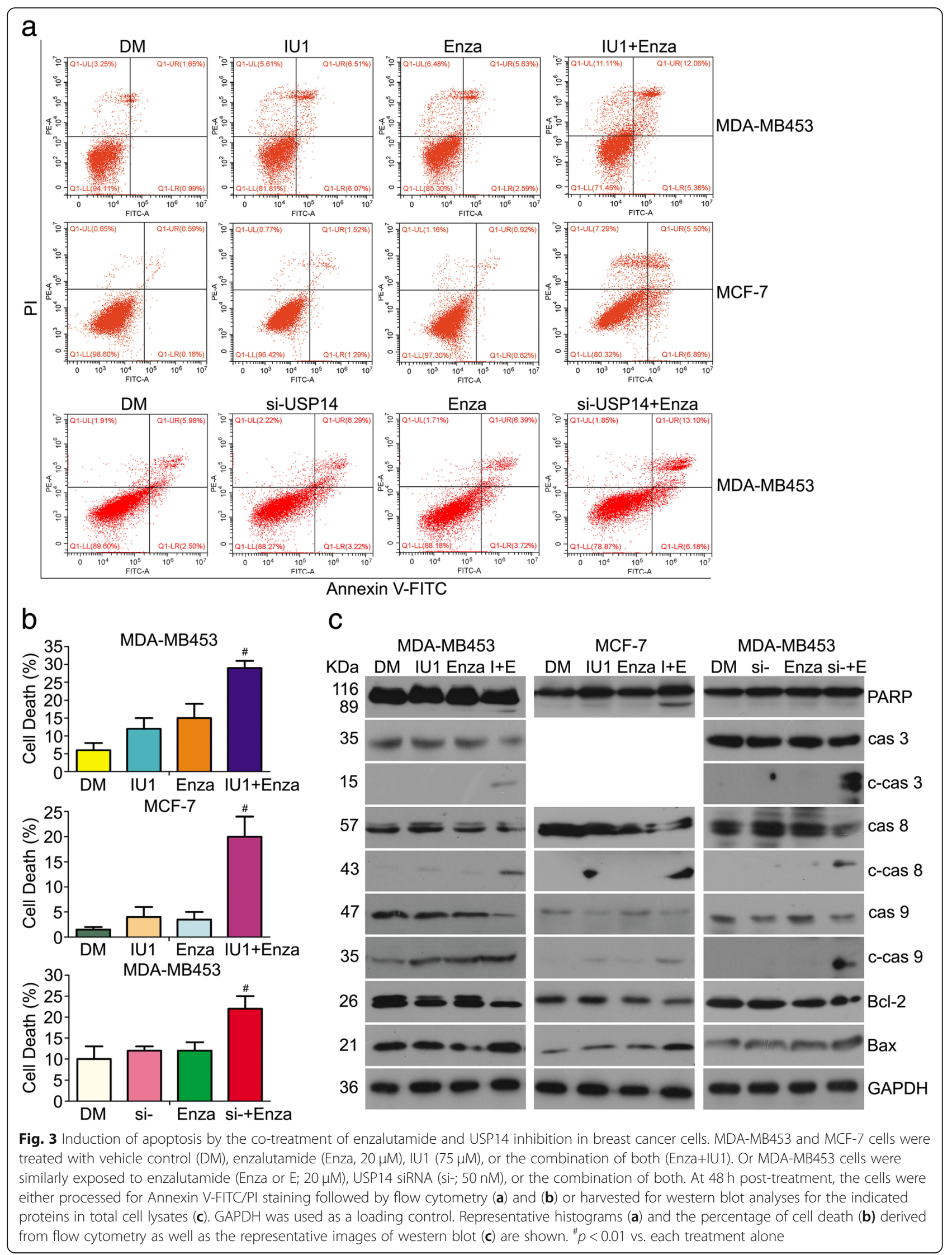




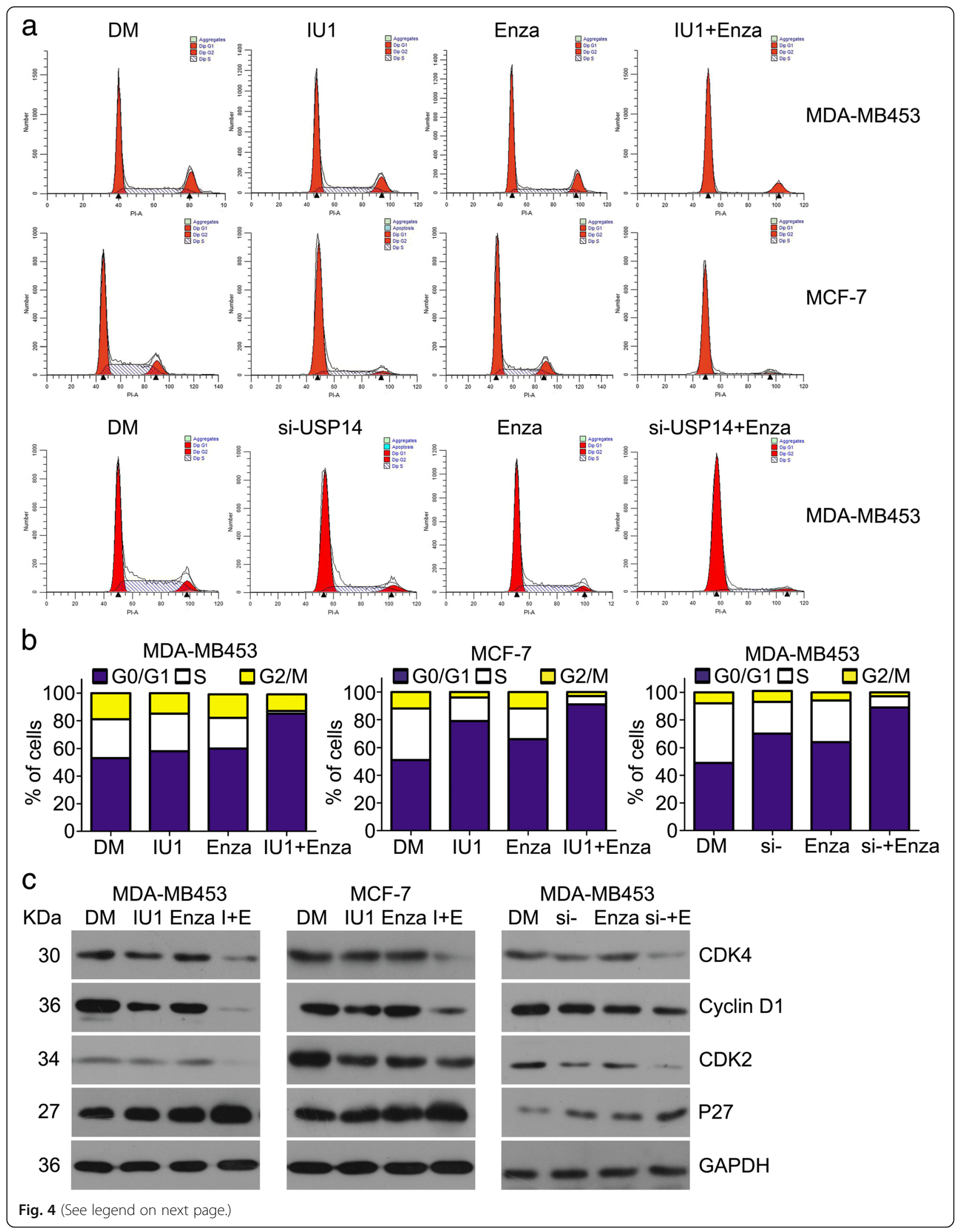


(See figure on previous page.)

Fig. 4 The treatment combining enzalutamide with USP14 inhibition arrests cell cycle progression MDA-MB453 and MCF-7 cells were treated with the indicated agents as described in Fig. 3 and then either processed for fluorescence-activated cell sorting analysis (FACS) to detect cell cycle distribution (a) and (b) or subject to total protein extraction for western blot analyses of the indicated cell cycle regulator proteins (c). GAPDH was used as a loading control. Representative images (a) and a summary of cell cycle distribution $\mathbf{b}$ derived from the FACS or representative images of the western blot analyses (c) are shown

inhibition (Fig. 5c-e). Although quite a few studies try to show the role of AR in breast cancer cells, the function of $\mathrm{AR}$ in breast cancer is not totally clear. To further confirm the role of AR in AR positive breast cancer cells. We explored the effect of AR depletion in breast cancer cells. We found that cell viability, proliferation and colony forming ability were suppressed by AR knockdown. Moreover, AR silence induced cell apoptosis in MDA-MB453 cells. Significantly, the results showed that AR depletion enhances enzalutamide induced-antiproliferative effect (Fig. S1a-d). These results indicated that induction of growth inhibition in co-treatment of enzalutamide and USP14 depletion could be a consequence of blocking AR signaling.

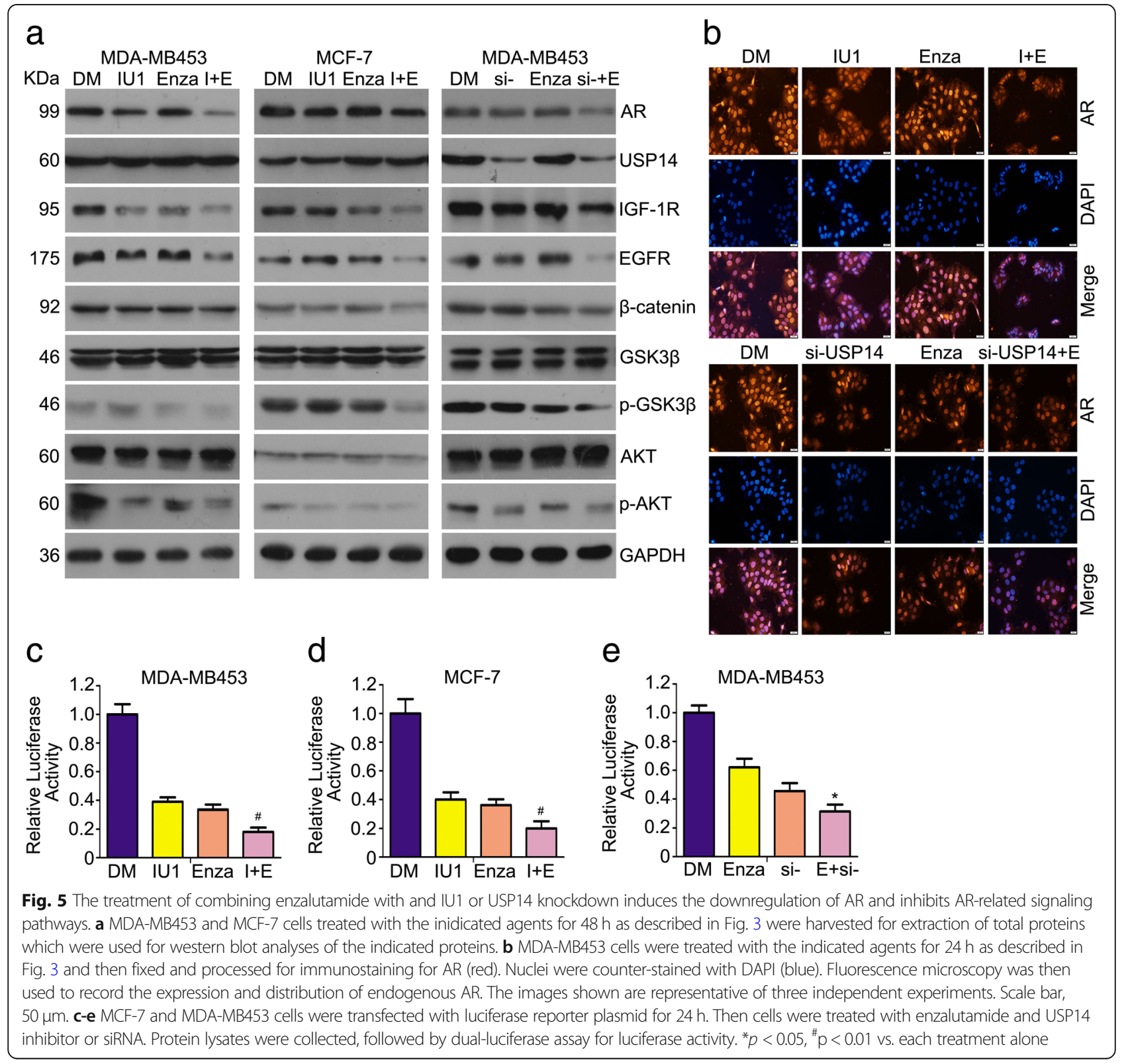


Synergistic growth inhibition by the co-treatment of enzalutamide and USP14 inhibition involves mechanisms more than suppressing AR-PI3K/AKT signaling

To better understand whether cell growth inhibition induced by the combination of USP14 inhibition and enzalutamide is associated with PI3K/AKT inhibition from the AR signaling suppression, the effect of AKT inhibitor (MK2206) on the cell survival and growth in MCF-7 and MDA-MB453 cells receiving the duo-treatment was examined. The MTS assays revealed that the molecular inhibitor of AKT increased the antiproliferation effect of enzalutamide+USP14 inhibition co-treatment (Fig. 6a). In addition to cell viability assay, we performed the colony formation assay and found that cell clonogenicity was decreased in the cells receiving MK2206 + enzalutamide+USP14 inhibition triple treatment, compared with enzalutamide+USP14 inhibition duo-treatment (Fig. 6b). The protein levels of CDK4 and Cyclin D1 were further decreased after adding MK2206 to the treatment of enzalutamide+IU1/USP14 siRNA. AKT inhibitor promoted the downregulation of AR protein induced by the combination of enzalutamide and IU1/USP14 knockdown and the cell cycle arrest was more remarkable in the triple treatment group (Fig. 6c). Moreover, the rates of cell death were significantly higher in the triple treatment group, compared with the enzalutamide+USP14 inhibition duo-treatment group (Fig. 6d). Inhibition of AKT exacerbated enzalutamide+IU1-induced the expression of cleaved caspase- 3 and PARP (Fig. 6e). These results suggest that although suppression of PI3K/AKT signaling is involved in the synergic antiproliferation effect resulting from the synergistic suppression of AR signaling by enzalutamide and USP14 inhibition, other antiproliferative mechanisms from USP14 inhibition may also contribute to the synergy.

\section{Co-treatment of enzalutamide and USP14 inhibition suppresses the growth of breast cancer in vivo}

Lastly, we tested the antitumor activity of the co-treatment of enzalutamide and IU1/USP14 knockdown in nude mice bearing tumor xenografts from MCF-7 breast cancer cells. Enzalutamide resulted in xenograft shrinkage and the similar result was obtained by IU1. Importantly, a synergic effect of enzalutamide in combination with IU1 on tumor growth inhibition was found upon co-administration of the two agents for 17 days (Fig. 7a-c); tumor volumes and tumor weight were remarkably declined in the combination therapy as compared with the enzalutamide or IU1 alone treatment. However, no obvious body weight loss happened during the experiments in nude mice treated with enzalutamide, IU1, or both (Fig. 7d). Subsequently, the level of AR, Ki67 and Bax were evaluated using immunochemical staining. We found that the expression of AR and Ki67, which promote proliferation, were decreased and Bax which promotes apoptosis was increased in the enzalutamide and IU1 combined treatment group (Fig. 7f). Apoptosis as indicated by TUNEL assays was increased in the combined treatment group as compared with either single drug treatment group (Fig. 7e). In separate cohort of mice, we implanted subcutaneously USP14-depleted MCF-7 cells stably expressing USP14-specific shRNA or control shRNA and monitored tumor growth as they were treated with enzalutamide or vehicle. Mice bearing USP14 shRNA-expressing MCF-7 cells showed decreased tumor growth compared with mice implanted with MCF-7 cells expressing control shRNA (Fig. 8a-c). More importantly, oral administration of enzalutamide exerted more effective tumor suppression in the USP14 shRNA group than in the control shRNA group as revealed by changes in the tumor volumes and weights whereas no difference in mouse body weight was observed among all groups (Fig. 8a-e). Immunochemical staining assay showed that AR, p-AKT and Ki67 expression were decreased and Bax expression were increased in the enzalutamide and USP14 shRNA combined group compared with the signal treatment (Fig. 8f).

\section{Discussion}

Enzalutamide, a second-generation AR antagonist, has been approved by the U.S. Food and Drug Administration for therapy in the patients with castration-resistant prostate cancer (CRPC) [41, 42]. Compared with the first-generation AR inhibitors, such as bicalutamide and flutamide, enzalutamide shows a higher anticancer potency resulting from better affinity to AR and inhibition of AR nuclear translocation [43-45]. Enzalutamide reduces the mortality of men with metastatic CRPC by $37 \%$ and prolongs the overall survival [45]. Increasing studies have demonstrated that enzalutamide is a good treatment strategy for triple negative breast cancer (TNBC) as well as CRPC similarly through targeting AR $[46,47]$. Clinical trials showed an anticancer effect of enzalutamide on patients with breast cancer, no matter it was combined with other chemotherapy or not [48].

Besides ER, PR and HER2, which promote the growth and progression of breast cancers, AR also may lead to the development of most breast cancers. AR has been identified as a potential therapeutic target in breast cancer, especially in the triple-negative breast cancer (TNBC) which shows the worst prognosis and metastases [49]. Studies have shown that ubiquitination regulates AR protein stability [21, 22]. Indeed, several DUBs have been explored to regulate AR protein levels and transactivation activity. USP7 modulates AR's chromatin biding and thereby regulates AR activity and USP12 not only stabilizes AR proteins but also promotes AR transactivation activity by weakening ubiquitin-dependent degradation [50,51]. Our previous studies has shown that USP14 can stabilize AR protein expression by trimming K48-linke ubiquitin chain on AR. Silencing or inhibiting 


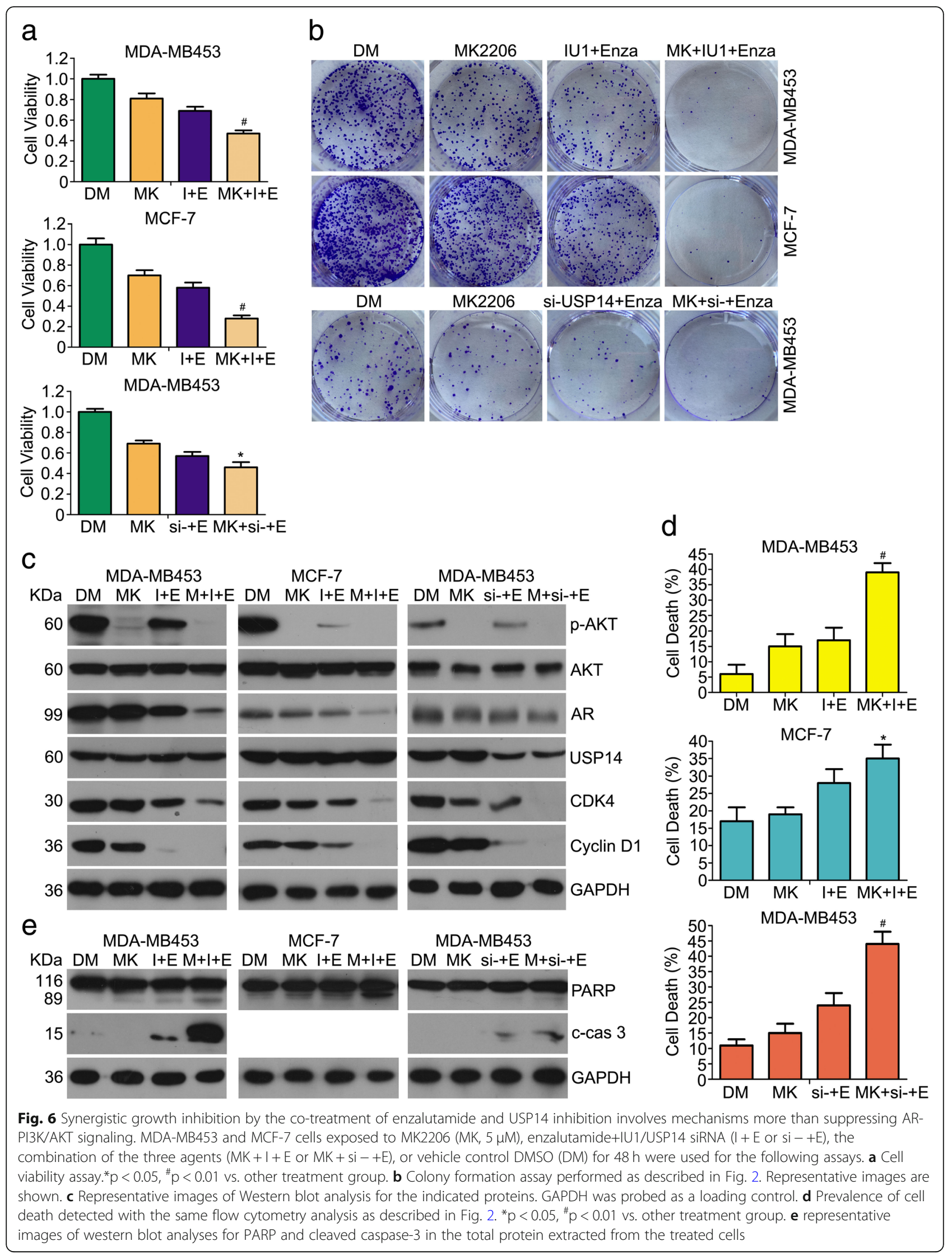




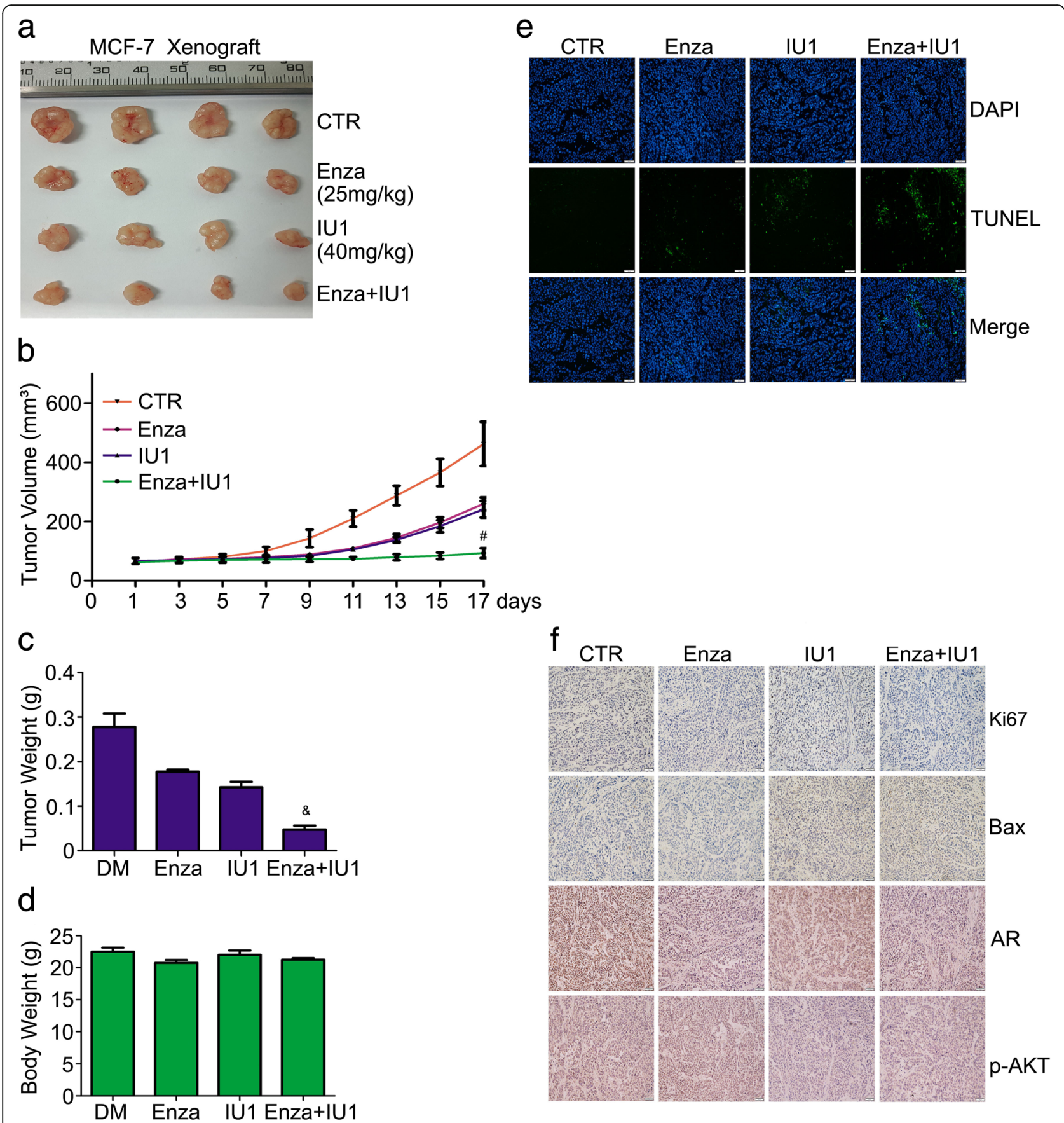

Fig. 7 Co-treatment of enzalutamide and USP14 inhibition suppresses the growth of breast cancer in vivo. BALB/c nude mice subcutaneously injected with MCF-7 cells were treated with enzalutamide $(25 \mathrm{mg} / \mathrm{kg})$, IU1 $(40 \mathrm{mg} / \mathrm{kg})$, or enzalutamide+IU1 for 17 days. Tumor volume (b) and mouse body weight (d) were measured every other day. At the end of 17 days of treatment, the tumor xenograft was excised, imaged (a), weighed (c), and further processed for TUNEL staining (e). Scale bar, $20 \mu \mathrm{m}$. And immunohistochemistry staining for AR, p-AKT, Bax and Ki67 (f). Scale bar, $50 \mu \mathrm{m} .{ }^{\#} \mathrm{p}<0.01,{ }^{\&} p<0.001$ vs. other treatment group

USP14 triggers cell growth inhibition and cell cycle arrest by decreasing AR level in AR-positive breast cancer cells $[21,22]$. However, no prior reported study has investigated whether USP14 inhibition in combination with AR antagonization has a benefit in treating breast cancer.
In the present study, we evaluated the effects of enzalutamide combined with USP14 inhibitor IU1 or with USP14 siRNA on breast cancer in vitro and in vivo. We have demonstrated that enzalutamide and USP14 inhibition synergistically inhibit cell viability in breast cancer 


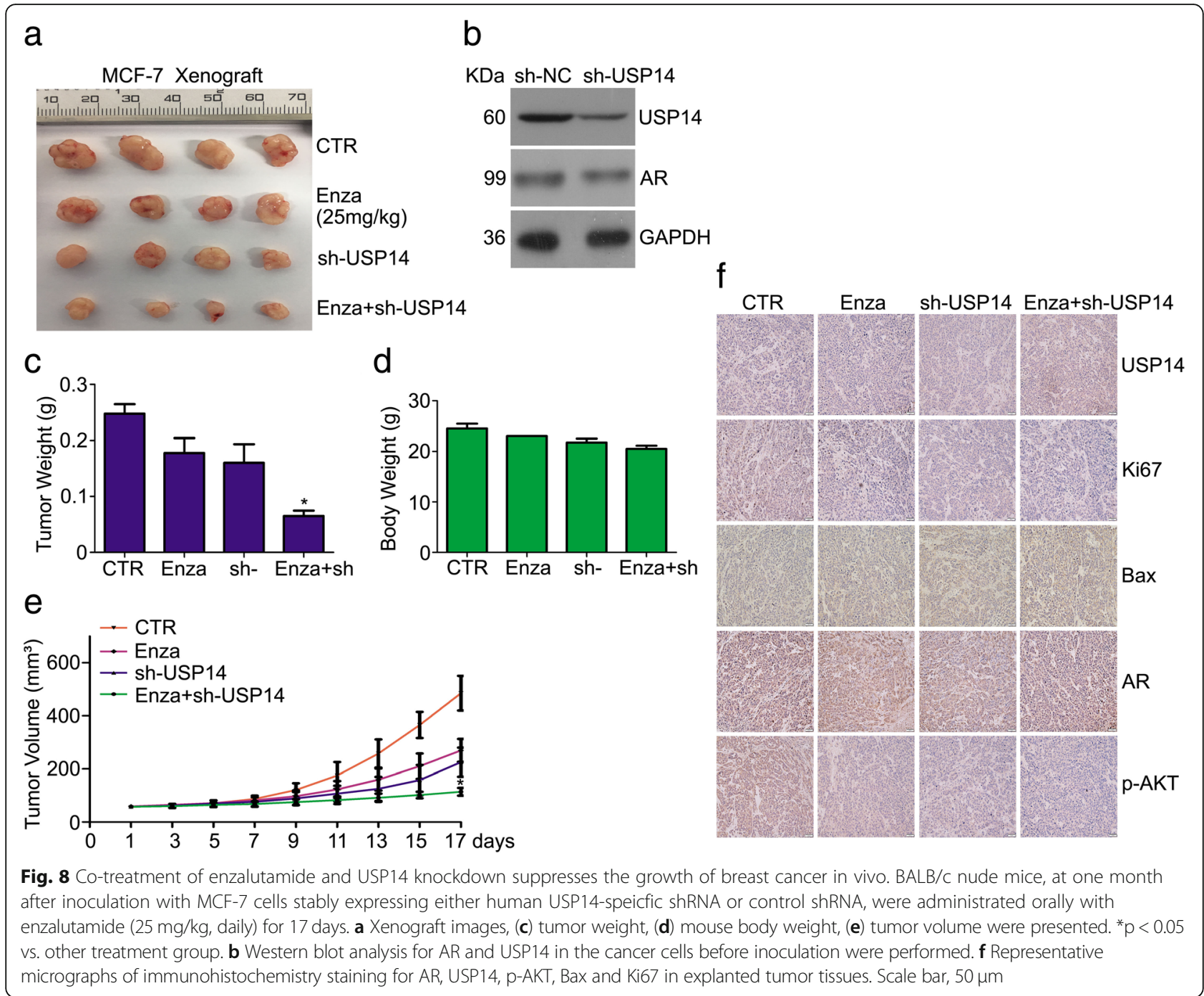

cells; this combined growth inhibition effect of the two agents is predominantly due to more effective induction of cell cycle arrest and cell apoptosis. Flow cytometry analysis showed increased percentage of cells at G0/G1 phase and elevated proportion of cell death in the cells treated with a combination of enzalutamide and IU1/USP14 siRNA, compared with those received the single agent treatment. In addition, enzalutamide promotes the decreases in proteins levels of CDK4, Cyclin D1 and CDK2 and the increase in P27 protein induced by IU1 or USP14 knockdown. The increases in the cleavage of caspase- $3,-8,-9$ and PARP, as well as downregulation of $\mathrm{Bcl}-2$ expression and elevation of Bax expression were more pronounced in the combined treatment group than in the single agent treatment groups. These findings indicate that activation of caspase pathway and mitochondrial dysfunction contribute to the anticancer synergy between enzalutamide and USP14 inhibition.
Both enzalutamide and USP14 inhibition can suppress AR signaling but they use different mechanisms to do that. As an AR antagonist, enzalutamide suppresses AR signaling at multiple steps, including competing with androgen in AR binding, blocking AR nuclear translocation, and preventing AR from binding the chromatin; USP14 inhibition, however, is known to destabilize AR protein and thereby reduce AR levels, which is confirmed in breast cancer cells by the present study. Therefore, we predicted that a treatment combining enzalutamide and USP14 inhibition should be more effective than the treatment with either single agent in terms of suppressing AR signaling in AR-positive breast cancer cells. Indeed, this prediction is well supported by our data. Enzalutamide alone did not cause a remarkable change in AR protein levels but USP14 inhibition alone or in combination with enzalutamide did. Furthermore, signaling events down stream of AR, such as the expression of IGF-1R,EGFR, and $\beta$-catenin, as well as GSK-3 $\beta$ 
and AKT phosphorylation, were more discernibly suppressed by the combination treatment than the single agent treatment (Fig. 5).

As an important non-stoichiometric DUB subunit of the $19 \mathrm{~S}$ proteasome, USP14 has essential functions to the cell beyond AR regulation [31, 52]. Hence, the synergy between enzalutamide and USP14 inhibition in antitumor effect on breast cancer also may be attributable to additional tumor suppressing actions from USP14 inhibition, beyond suppressing AR signaling. This is underscored by the results from the AKT inhibition experiment (Fig. 6). AKT inhibition with a small molecule inhibitor (MK2206) alone induced growth inhibition and cell death, to the extent comparable to the treatment combining enzalutamide and USP14 inhibition; however, the treatment combining all three (i.e., enzalutamide + USP14 inhibition + AKT inhibition) showed significant greater effects than the former two treatment regimen (Fig. 6). Hence, it is very likely that suppressing the AR-PI3K/AKT signaling pathway participates in the synergy in the antiproliferation and proapoptosis between enzalutamide and USP14 inhibition while other mechanisms from USP14 inhibition also come into play. Importantly, the synergy in in the cytostatic effect on breast cancer cells between enzalutamide and IU1 or USP14 knockdown observed in cell cultures has been confirmed by our mouse xenograft experiments. Enzalutamide in combination with either pharmacological inhibition of USP14 with IU1 or shRNA-mediated USP14 knockdown were able to more effectively reduce tumor volumes and tumor weights than treatment with enzalutamide or USP14 inhibition alone, without discernibly altering mouse body weights, which also suggests that the two drug regimen is safe and well-tolerated.

\section{Conclusion}

In summary, this study demonstrates a potential advantage of enzalutamide in combination of USP14 inhibition in AR-positive breast cancer treatment, compared with the treatment with each alone. By synergistically targeting AR-dependent and -independent pathways, this new combination treatment strategy may provide a potentially novel regimen for the treatment of AR-positive breast cancer in humans.

\section{Additional file}

Additional file 1: Figure S1. Enzalutamide induced-antiproliferation is regulated by silencing AR or overexpressing USP14. (DOCX $422 \mathrm{~kb}$ )

\section{Abbreviations}

AR: Androgen receptor; BCa: Breast cancer; CRPC: castration-resistant prostate cancer; DUBs: deubiquitinating enzymes; ER: estrogen receptor; HER2: human epidermal growth factor receptor 2; IGF-1R: IGF-1 receptor; PR: progesterone receptor; TNBC: triple-negative breast cancer

\section{Acknowledgements}

We thank Guangdong Provincial Key Laboratory of Malignant Tumor Epigenetics and Gene Regulation, Sun Yat-Sen Memorial Hospital, Sun YatSen University for flow cytometry analysis.

\section{Funding}

The study was supported by the National Natural Science Foundation of China $(81670156,81872151,81773213)$, The National Funds for Developing Local Colleges and Universities (B16056001), Natural Science Foundation research team of Guangdong Province (2018B030312001), the Science and Technology Program of Guangzhou (201604020001), Innovative Academic Team of Guangzhou Education System (1201610014), the Project of Department of Education of Guangdong Province(2016KTSCX119), the Research Team of Department of Education of Guangdong

Province(2017KCXTD027), Guangzhou key medical discipline construction project fund.

\section{Availability of data and materials}

All the data and materials supporting the conclusions were included in the main paper.

\section{Authors' contributions}

$\mathrm{HBH}$ and JBL designed the experiments. $\mathrm{XHX}, \mathrm{CYH}, \mathrm{YNL}, \mathrm{YL}, \mathrm{ZCH}, \mathrm{ZQG}$ and $\mathrm{LLJ}$ performed the experiments, $\mathrm{HBH}, \mathrm{JBL}$ and XJW wrote the manuscript. All authors read and approved the final manuscript.

\section{Ethics approval and consent to participate}

The use and care of experimental animals were approved by the Institutional Animal Care and Use Committee of Guangzhou Medical University.

Consent for publication

Not applicable.

\section{Competing interests}

The authors declare no conflicts of interest.

\section{Publisher's Note}

Springer Nature remains neutral with regard to jurisdictional claims in published maps and institutional affiliations.

\section{Author details}

${ }^{1}$ Affiliated Cancer Hospital and institute of Guangzhou Medical University; Key Laboratory of Protein Modification and Degradation; State Key Laboratory of Respiratory Disease, School of Basic Medical Sciences, Guangzhou Medical University, Guangzhou 510095, Guangdong, China.

${ }^{2}$ Division of Basic Biomedical Sciences, Sanford School of Medicine of the University of South Dakota, Vermillion, SD 57069, USA.

Received: 28 January 2019 Accepted: 13 May 2019

Published online: 24 May 2019

\section{References}

1. Christopoulos PF, Vlachogiannis NI, Vogkou CT, Koutsilieris M. The role of the androgen receptor signaling in breast malignancies. Anticancer Res. 2017;37:6533-40.

2. Siegel RL, Miller KD, Jemal A. Cancer statistics, 2017. CA Cancer J Clin. 2017; 67:7-30.

3. Perou CM, Sorlie T, Eisen MB, van de Rijn M, Jeffrey SS, Rees CA, Pollack JR, Ross DT, Johnsen H, Akslen LA, et al. Molecular portraits of human breast tumours. Nature. 2000;406:747-52.

4. Sorlie T, Perou CM, Tibshirani R, Aas T, Geisler S, Johnsen H, Hastie T, Eisen $M B$, van de Rijn M, Jeffrey SS, et al. Gene expression patterns of breast carcinomas distinguish tumor subclasses with clinical implications. Proc Natl Acad Sci U S A. 2001:98:10869-74.

5. Early Breast Cancer Trialists' Collaborative G. Effects of chemotherapy and hormonal therapy for early breast cancer on recurrence and 15-year survival: an overview of the randomised trials. Lancet. 2005;365:1687-717.

6. Jones KL, Buzdar AU. Evolving novel anti-HER2 strategies. Lancet Oncol. 2009;10:1179-87. 
7. Bianchini G, Balko JM, Mayer IA, Sanders ME, Gianni L. Triple-negative breast cancer: challenges and opportunities of a heterogeneous disease. Nat Rev Clin Oncol. 2016;13:674-90.

8. Denkert C, Liedtke C, Tutt A, von Minckwitz G. Molecular alterations in triple-negative breast cancer-the road to new treatment strategies. Lancet. 2017:389:2430-42.

9. Giovannelli P, Di Donato M, Galasso G, Di Zazzo E, Bilancio A, Migliaccio A. The androgen receptor in breast Cancer. Front Endocrinol (Lausanne). 2018;9:492.

10. Thorek DL, Ku AT, Mitsiades N, Veach D, Watson PA, Metha D, Strand SE, Sharma SK, Lewis JS, Abou DS, et al. Harnessing androgen receptor pathway activation for targeted alpha particle Radioimmunotherapy of breast Cancer. Clin Cancer Res. 2019;25:881-91.

11. Kono M, Fujii T, Lim B, Karuturi MS, Tripathy D, Ueno NT. Androgen receptor function and androgen receptor-targeted therapies in breast Cancer: a review. JAMA Oncol. 2017:3:1266-73.

12. Beer TM, Armstrong AJ, Rathkopf D, Loriot Y, Sternberg CN, Higano CS, Iversen P, Evans CP, Kim CS, Kimura G, et al. Enzalutamide in men with chemotherapy-naive metastatic castration-resistant prostate Cancer: extended analysis of the phase 3 PREVAlL study. Eur Urol. 2017;71:151-4.

13. Chen CD, Welsbie DS, Tran C, Baek SH, Chen R, Vessella R, Rosenfeld MG, Sawyers CL. Molecular determinants of resistance to antiandrogen therapy. Nat Med. 2004;10:33-9.

14. Guerrero J, Alfaro IE, Gomez F, Protter AA, Bernales S. Enzalutamide, an androgen receptor signaling inhibitor, induces tumor regression in a mouse model of castration-resistant prostate cancer. Prostate. 2013;73: 1291-305.

15. Tran C, Ouk S, Clegg NJ, Chen Y, Watson PA, Arora V, Wongvipat J, Smith-Jones PM, Yoo D, Kwon A, et al. Development of a second-generation antiandrogen for treatment of advanced prostate cancer. Science. 2009;324:787-90.

16. Traina TA, Miller K, Yardley DA, Eakle J, Schwartzberg LS, O'Shaughnessy J, Gradishar W, Schmid P, Winer E, Kelly C, et al. Enzalutamide for the treatment of androgen receptor-expressing triple-negative breast Cancer. J Clin Oncol. 2018;36:884-90.

17. Hussain S, Zhang Y, Galardy PJ. DUBs and cancer: the role of deubiquitinating enzymes as oncogenes, non-oncogenes and tumor suppressors. Cell Cycle. 2009;8:1688-97.

18. D'Arcy P, Linder S. Molecular pathways: translational potential of deubiquitinases as drug targets. Clin Cancer Res. 2014;20:3908-14.

19. Tian Z, D'Arcy P, Wang X, Ray A, Tai YT, Hu Y, Carrasco RD, Richardson $P$, Linder $S$, Chauhan D, Anderson KC. A novel small molecule inhibitor of deubiquitylating enzyme USP14 and UCHL5 induces apoptosis in multiple myeloma and overcomes bortezomib resistance. Blood. 2014; 123:706-16.

20. Mialki RK, Zhao J, Wei J, Mallampalli DF, Zhao Y. Overexpression of USP14 protease reduces I-kappaB protein levels and increases cytokine release in lung epithelial cells. J Biol Chem. 2013;288:15437-41.

21. Liao Y, Liu N, Hua X, Cai J, Xia X, Wang X, Huang H, Liu J. Proteasomeassociated deubiquitinase ubiquitin-specific protease 14 regulates prostate cancer proliferation by deubiquitinating and stabilizing androgen receptor. Cell Death Dis. 2017;8:e2585

22. Liao Y, Xia X, Liu N, Cai J, Guo Z, Li Y, Jiang L, Dou QP, Tang D, Huang H, Liu J. Growth arrest and apoptosis induction in androgen receptor-positive human breast cancer cells by inhibition of USP14-mediated androgen receptor deubiquitination. Oncogene. 2018;37:1896-910.

23. Huang H, Guo M, Liu N, Zhao C, Chen H, Wang X, Liao S, Zhou P, Liao Y, Chen $X$, et al. Bilirubin neurotoxicity is associated with proteasome inhibition. Cell Death Dis. 2017;8:e2877.

24. Xia X, Liao Y, Guo Z, Li Y, Jiang L, Zhang F, Huang C, Liu Y, Wang X, Liu N, et al. Targeting proteasome-associated deubiquitinases as a novel strategy for the treatment of estrogen receptor-positive breast cancer. Oncogenesis. 2018;7:75.

25. Huang H, Hua X, Liu N, Li X, Liu S, Chen X, Zhao C, Lan X, Yang C, Dou QP, Liu J. Anacardic acid induces cell apoptosis associated with induction of ATF4-dependent endoplasmic reticulum stress. Toxicol Lett. 2014;228:170-8

26. Huang H, Zhang X, Li S, Liu N, Lian W, McDowell E, Zhou P, Zhao C, Guo H, Zhang $C$, et al. Physiological levels of ATP negatively regulate proteasome function. Cell Res. 2010;20:1372-85.

27. Li X, Liu S, Huang H, Liu N, Zhao C, Liao S, Yang C, Liu Y, Zhao C, Li S, et al. Gambogic acid is a tissue-specific proteasome inhibitor in vitro and in vivo. Cell Rep. 2013;3:211-22.
28. Huang H, Liu N, Liao Y, Liu N, Cai J, Xia X, Guo Z, Li Y, Wen Q, Yin Q, et al. Platinum-containing compound platinum pyrithione suppresses ovarian tumor proliferation through proteasome inhibition. J Exp Clin Cancer Res. 2017:36:79.

29. Huang H, Liao Y, Liu N, Hua X, Cai J, Yang C, Long H, Zhao C, Chen X, Lan $X$, et al. Two clinical drugs deubiquitinase inhibitor auranofin and aldehyde dehydrogenase inhibitor disulfiram trigger synergistic anti-tumor effects in vitro and in vivo. Oncotarget. 2016;7:2796-808.

30. Shi X, Chen X, Li X, Lan X, Zhao C, Liu S, Huang H, Liu N, Liao S, Song W, et al. Gambogic acid induces apoptosis in imatinib-resistant chronic myeloid leukemia cells via inducing proteasome inhibition and caspase-dependent Bcr-Abl downregulation. Clin Cancer Res. 2014;20:151-63.

31. Lee BH, Lee MJ, Park S, Oh DC, Elsasser S, Chen PC, Gartner C, Dimova N, Hanna J, Gygi SP, et al. Enhancement of proteasome activity by a smallmolecule inhibitor of USP14. Nature. 2010;467:179-84.

32. Salic A, Mitchison TJ. A chemical method for fast and sensitive detection of DNA synthesis in vivo. Proc Natl Acad Sci U S A. 2008;105:2415-20.

33. Savitskaya MA, Onishchenko GE. Mechanisms of apoptosis. Biochemistry (Mosc). 2015;80:1393-405.

34. Hanahan D, Weinberg RA. Hallmarks of cancer: the next generation. Cell. 2011;144:646-74.

35. Moe RE, Anderson BO. Androgens and androgen receptors: a clinically neglected sector in breast cancer biology. J Surg Oncol. 2007;95: 437-9.

36. Pandini G, Mineo R, Frasca F, Roberts CT Jr, Marcelli M, Vigneri R, Belfiore A. Androgens up-regulate the insulin-like growth factor-l receptor in prostate cancer cells. Cancer Res. 2005;65:1849-57.

37. Schayek H, Seti H, Greenberg NM, Sun S, Werner H, Plymate SR. Differential regulation of insulin-like growth factor-I receptor gene expression by wild type and mutant androgen receptor in prostate cancer cells. Mol Cell Endocrinol. 2010;323:239-45.

38. Mandel A, Larsson P, Sarwar M, Semenas J, Syed Khaja AS, Persson JL. The interplay between AR, EGF receptor and MMP-9 signaling pathways in invasive prostate cancer. Mol Med. 2018;24:34.

39. Lehmann BD, Bauer JA, Schafer JM, Pendleton CS, Tang L, Johnson KC, Chen X, Balko JM, Gomez H, Arteaga CL, et al. PIK3CA mutations in androgen receptorpositive triple negative breast cancer confer sensitivity to the combination of PI3K and androgen receptor inhibitors. Breast Cancer Res. 2014;16:406.

40. Premanand A, Reena Rajkumari B. Androgen modulation of Wnt/beta-catenin signaling in androgenetic alopecia. Arch Dermatol Res. 2018;310:391-9.

41. Beer TM, Tombal B. Enzalutamide in metastatic prostate cancer before chemotherapy. N Engl J Med. 2014;371:1755-6.

42. Scher HI, Beer TM, Higano CS, Anand A, Taplin ME, Efstathiou E, Rathkopf D, Shelkey J, Yu EY, Alumkal J, et al. Antitumour activity of MDV3100 in castrationresistant prostate cancer: a phase 1-2 study. Lancet. 2010;375:1437-46.

43. Farrow JM, Yang JC, Evans CP. Autophagy as a modulator and target in prostate cancer. Nat Rev Urol. 2014;11:508-16.

44. Loriot Y, Bianchini D, lleana E, Sandhu S, Patrikidou A, Pezaro C, Albiges L, Attard G, Fizazi K, De Bono JS, Massard C. Antitumour activity of abiraterone acetate against metastatic castration-resistant prostate cancer progressing after docetaxel and enzalutamide (MDV3100). Ann Oncol. 2013;24:1807-12.

45. Scher HI, Fizazi K, Saad F, Taplin ME, Sternberg CN, Miller K, de Wit R, Mulders P, Chi KN, Shore ND, et al. Increased survival with enzalutamide in prostate cancer after chemotherapy. N Engl J Med. 2012;367:1187-97.

46. Caiazza F, Murray A, Madden SF, Synnott NC, Ryan EJ, O'Donovan N, Crown J, Duffy MJ. Preclinical evaluation of the AR inhibitor enzalutamide in triplenegative breast cancer cells. Endocr Relat Cancer. 2016;23:323-34.

47. Cochrane DR, Bernales S, Jacobsen BM, Cittelly DM, Howe EN, D'Amato NC, Spoelstra NS, Edgerton SM, Jean A, Guerrero J, et al. Role of the androgen receptor in breast cancer and preclinical analysis of enzalutamide. Breast Cancer Res. 2014;16:R7.

48. Schwartzberg LS, Yardley DA, Elias AD, Patel M, LoRusso P, Burris HA, Gucalp A, Peterson AC, Blaney ME, Steinberg $J$, et al. A phase I/lb study of Enzalutamide alone and in combination with endocrine therapies in women with advanced breast Cancer. Clin Cancer Res. 2017;23:4046-54.

49. Qin J, Zhou Z, Chen W, Wang C, Zhang H, Ge G, Shao M, You D, Fan Z, Xia $\mathrm{H}$, et al. BAP1 promotes breast cancer cell proliferation and metastasis by deubiquitinating KLF5. Nat Commun. 2015;6:8471. 
50. Burska UL, Harle VJ, Coffey K, Darby S, Ramsey H, O'Neill D, Logan IR, Gaughan L, Robson CN. Deubiquitinating enzyme Usp12 is a novel coactivator of the androgen receptor. J Biol Chem. 2013;288:32641-50.

51. Chen ST, Okada M, Nakato R, Izumi K, Bando M, Shirahige K. The Deubiquitinating enzyme USP7 regulates androgen receptor activity by modulating its binding to chromatin. J Biol Chem. 2015;290:21713-23.

52. Liu N, Kong T, Chen X, Hu H, Gu H, Liu S, Chen X, Yang Q, Li A, Xiong X, Zhang Z. Ubiquitin-specific protease 14 regulates LPS-induced inflammation by increasing ERK1/2 phosphorylation and NF-kappaB activation. Mol Cell Biochem. 2017;431:87-96.

Ready to submit your research? Choose BMC and benefit from:

- fast, convenient online submission

- thorough peer review by experienced researchers in your field

- rapid publication on acceptance

- support for research data, including large and complex data types

- gold Open Access which fosters wider collaboration and increased citations

- maximum visibility for your research: over $100 \mathrm{M}$ website views per year

At $\mathrm{BMC}$, research is always in progress.

Learn more biomedcentral.com/submissions 